\title{
Assessment of Heavy Metals and Metalloids Contamination in the Surface Sediments of the Xiangjiang River, Hunan, China
}

\author{
Yu Zhong ${ }^{1}$, Guangyi Fu ${ }^{1, *}$, Renjun Xiang ${ }^{1}$, Fubing Yao $^{2,3}$, Youze Xu${ }^{1}$, Yingxiang Cheng ${ }^{1}$, Zhan Liu ${ }^{1}$, Tao Wen ${ }^{1}$, Guanming \\ Zeng 2,3 \\ ${ }^{1}$ Key Laboratory of Water Pollution Control Technology, Hunan Research Academy of Environmental Sciences, 410004 Changsha, \\ China \\ ${ }^{2}$ College of Environmental Science and Engineering, Hunan University, 410082 Changsha, China \\ ${ }^{3}$ Key Laboratory of Environmental Biology and Pollution Control, Hunan University, Ministry of Education, 410082 Changsha, China
}

\begin{abstract}
In this study, the Qingshuitang District from the Shifeng Bridge to the Majiahe Bridge was selected as study areas to assess the contamination status and release amount of heavy metals from the surface sediments of the Xiangjiang River, Hunan Province, China. A sum of five surface sediment samples were collected, and the total contents of $\mathrm{Cu} 、 \mathrm{~Pb} 、 \mathrm{Zn} 、 \mathrm{Cd} 、 \mathrm{Cr} 、 \mathrm{Mn} 、 \mathrm{As}$ and $\mathrm{Hg}$ in these samples were measured by the Inductively Coupled Plasma Mass Spectrometry (ICP-MS) and Atom Absorption Spectrophotometer (AAS). Results showed that the average contents of Cd and As in the sediments were higher than the Grade III of the China Environmental Quality Standard for Soils. Moreover, release experiments were carried out to study the effect of flow velocity and $\mathrm{pH}$ values on the release of heavy metals from the sediments. The results suggested that increased the flow velocity and decreased the $\mathrm{pH}$ of overlying water could promote the release of heavy metals, while the release amount of four heavy metals were too small and the largest release amount of Mn was only $7.50 \mu \mathrm{g} /(\mathrm{g} \cdot \mathrm{d})$. It suggested that the release of heavy metals from the sediments into the overlying water is a slow and long-term process.
\end{abstract}

\section{Introduction}

The Xiangjiang River is one of the seven major branches of the Yangtze River and the largest river in the Dongting Lake water system. Due to industrial structure and historical reasons, the Qingshuitang District of the Xiangjiang River is considered to be one of the most polluted areas in China [1]. After decades of comprehensive treatment, the wastewater discharged into the river has been greatly reduced and the water quality of the Xiangjiang River significantly improved. When the exogenous heavy metals pollution of river was controlled, the contaminated sediments in these areas were the potential nonpoint sources of heavy metals and metalloids for the Xiangjiang River [1,2]. For one thing, with the change of the water environmental conditions (temperature, $\mathrm{pH}$, flow velocity, redox conditions, etc.), the contaminated sediments would release heavy metals and metalloids into overlying waters, which may increases the heavy metals content of overlying waters and poses environmental risk to the fluvial ecosystems [3]. For another, the contaminated sediments are the important living places and food sources for the benthic organisms, which may endanger human health and ecological environment when the heavy metals entering the food chain directly or indirectly.

Due to the potential ecological hazards of contaminated sediments, the majority of researches have paid more attention to assess the heavy metals source and ecological risk of sediments in the Xiangjiang River. Jiang et al. [1] analyzed contents and fractions of four heavy metals $(\mathrm{Cd}, \mathrm{Cu}, \mathrm{Pb}$ and $\mathrm{Zn})$ covering both sediments and soils in Qingshuitang District, the results showed this area was severely polluted by the four heavy metals, and the total concentrations exceeded the Chinese environmental quality standard for soil, grade III, especially for Cd. Wang et al. [4] investigated heavy metal pollution of soils and vegetables in the midstream and downstream of the Xiangjiang River, the results suggested that there are significant positive correlations between the concentrations of $\mathrm{Cd}, \mathrm{Pb}$ and $\mathrm{Zn}$ in vegetables and the concentrations in the corresponding vegetable soils. Chai et al. [5] investigated the contamination status and the ecological risk of heavy metal contaminations in the Xiangiiang River, the results showed that potential ecological risk index of $\mathrm{Cd}, \mathrm{Pb}, \mathrm{Zn}$, and $\mathrm{Cu}$ caused severe contaminated and posed very high potential ecological risk to the Xiangjiang River. From above, the contamination status and the ecological risk of heavy metal contamination in the sediments of the Xiangjiang River have been systematically reported [4-6]. However, there is still little information on the release rules and long-term release amount of heavy metals in the sediments of the Xiangjiang River.

In this study, the contamination of heavy metals and metalloids $(\mathrm{Cu}, \mathrm{Pb}, \mathrm{Zn}, \mathrm{Cd}, \mathrm{Cr}, \mathrm{Mn}, \mathrm{As}$ and $\mathrm{Hg})$ in the 
surface sediments of the Xiangjiang River were assessed. Meanwhile, the effects of flow velocity and $\mathrm{pH}$ value on the release of heavy metal from the sediments were studied by the self-designed simulation system.

\section{Materials and methods}

\subsection{Sample collecting}

The Qingshuitang District from the Shifeng Bridge to the Majiahe Bridge was selected as study areas, and the specific five sampling sites are shown in Table 1. Three surface sediment (depth $0-5 \mathrm{~cm}$ ) samples for each sampling site were collected by a grab sampler (ZYC-200B, China) and stored in clean plastic bucket prior to shipping to the laboratories. The surface water samples at the site of the sediments were also collected in plastic bucket for physicochemical analysis and simulation experiment. These buckets were stored in refrigerator at $4{ }^{\circ} \mathrm{C}$ before analysis. All the chemicals used in this experiment were of analytical reagent grade and purchased from Kermel Chemical Reagent Co. Ltd. (Tianjin, China).

Table 1. Distribution of five sampling sites in the Qingshuitang District of the Xiangjiang River.

\begin{tabular}{|c|c|c|c|}
\hline $\begin{array}{c}\text { Sampling } \\
\text { number }\end{array}$ & Sampling sites & $\begin{array}{c}\text { Sampling sites } \\
\text { longitude }\end{array}$ & $\begin{array}{c}\text { Sampling sites } \\
\text { latitude }\end{array}$ \\
\hline A & Shifeng Bridge & 113.107301 & 27.856671 \\
\hline B & Panjiawu village & 113.089820 & 27.860743 \\
\hline C & $\begin{array}{c}\text { Majiahe monitor } \\
\text { station }\end{array}$ & 113.053385 & 27.856016 \\
\hline D & Majiahe upstream & 113.042677 & 27.849500 \\
\hline E & Majiahe Bridge & 113.037359 & 27.844645 \\
\hline
\end{tabular}

\subsection{Experimental procedure}

A pollutant release system was designed as shown in Fig. 1. This system consisted of polyethylene plastic cylinder (outer diameter $0.9 \mathrm{~m}$ and inner diameter $0.5 \mathrm{~m}$ ) as an annular tank, a multi-function water quality analyzer, a motor stirrer and a peristaltic pump. In order to study the release amount of heavy metal, the collected sediments were added to the annular tank and the effective height of the sediments was about 2 to $3 \mathrm{~cm}$. Then the water samples were added to the annular tank under the controlled conditions.

To determine the effects of flow velocity on the release of heavy metal from the sediments, the velocity of water in the annular tank was set to $0.6,0.9$ and 1.2 $\mathrm{m} / \mathrm{s}$ according to the long-term monitoring data of the Xiangjiang River (the historical data was 0.829-1.144 $\mathrm{m} / \mathrm{s}$ ). To evaluate the effects of $\mathrm{pH}$ value on the release of heavy metal from the sediments, $\mathrm{pH}$ value of water samples was adjusted to 6.0, 7.9 and 9.0 in buffer tank, and then pumped into the annular tank. The release experiments were continuously performed for a month at the temperature of $25 \pm 1{ }^{\circ} \mathrm{C}$, the water samples and sediment samples were collected at fixed time through the sampling aperture, and stored in tightly capped bottles at the refrigerator for testing.

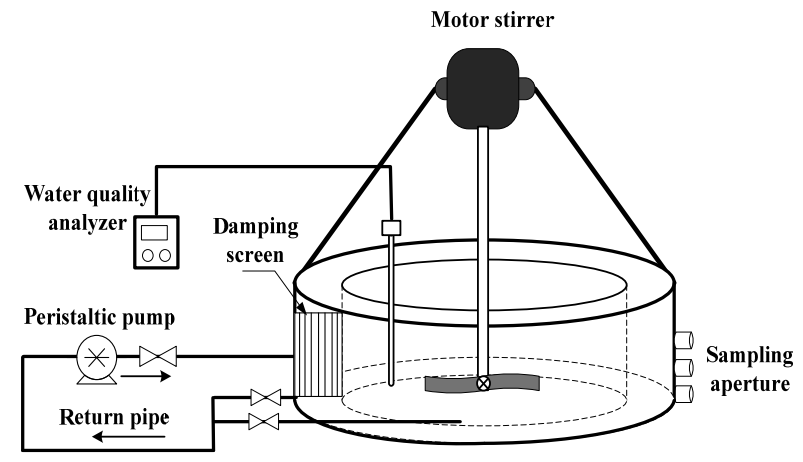

Fig. 1. A schematic view of sediment pollutants release system.

\subsection{Analytical methods}

For the total heavy metal contents detection, the sediment samples were air-dried for 14 days, ground to pass through a $0.149 \mathrm{~mm}$ sieve, and followed by desiccation at $110{ }^{\circ} \mathrm{C}$ for 2 days. After that, $0.1 \mathrm{~g}$ well-prepared samples were completely placed in Teflon tubes and digested with $\mathrm{HNO}_{3}, \mathrm{HF}$, and $\mathrm{HClO}_{4}$. Then the solutions were diluted with $2 \%$ (v/v) $\mathrm{HNO}_{3}$ to a final volume of 50 $\mathrm{mL}$, and the concentrations of $\mathrm{Cu}, \mathrm{Pb}, \mathrm{Zn}, \mathrm{Cd}, \mathrm{Cr}, \mathrm{Mn}$ and $\mathrm{Hg}$ were simultaneously determined with an Inductively Coupled Plasma Mass Spectrometry (ICP-MS, Agilent 7500 series, USA). The concentration of As was analyzed with an Atomic Fluorescence Spectrometer (AFS-2202, Beijing Haiguang Instrumental Co., China). The $\mathrm{pH}$ was measured using a standard glass electrode and $\mathrm{pH}$ meter (pHS-3C model, Leici, China). All the tests were performed in duplicate at least.

\section{Results and discussion}

\subsection{Heavy metal concentrations of sediments}

The heavy metals and metalloids concentration of $\mathrm{Cu}, \mathrm{Pb}$, $\mathrm{Zn}, \mathrm{Cd}, \mathrm{Cr}, \mathrm{Mn}, \mathrm{As}$ and $\mathrm{Hg}$ in the sediments are shown in Table 1. The results showed that $\mathrm{pH}$ value of samples varied from 7.4 to 8.1 , indicating the sediment of the Xiangjiang River is moderately alkaline in nature. The contents of $\mathrm{Cu}$ and $\mathrm{Pb}$ were 41.2-75.9 and 60.7-113 $\mathrm{mg} / \mathrm{kg}$ dry weight, respectively. The contents of $\mathrm{Cr}$ and $\mathrm{Hg}$ varied from 83.4 to $122 \mathrm{mg} / \mathrm{kg}$ and from 0.287 to $0.608 \mathrm{mg} / \mathrm{kg}$, respectively. The mean concentration of these heavy metals did not exceeded the Grade III of the China Environmental Quality Standard for Soils (CEQSS, GB15618-1995). The total concentration of $\mathrm{Zn}$ varied from 246 to $755 \mathrm{mg} / \mathrm{kg}$, and the $\mathrm{Zn}$ content of three sampling sites (B, C, and D) were higher than the limit value specified in the Grade III of CEQSS, which was likely to be related to wastewater discharge from zinc smelting factories in these regions [5]. Similar results were shown in the previous researches on the Xiangjiang River [2]. The contents of $\mathrm{Cd}$ and As varied from 5.88 to $15.4 \mathrm{mg} / \mathrm{kg}$ and from 60.1 to $121 \mathrm{mg} / \mathrm{kg}$, respectively. The $\mathrm{Cd}$ and As contents of five sampling points exceeded the Grade III of CEQSS. These two heavy metals can cause chronic poisoning and induce various diseases if they 
accumulate in the human body [7].

The range of Mn content was 1024-1881 mg/kg, and the highest content appeared at sampling site E. Due to the lack of the limits value of $\mathrm{Mn}$ in the CEQSS, the arithmetic mean of $583 \mathrm{mg} / \mathrm{kg}$ for background level of China was referenced [8]. The Mn content of five sampling sites exceeded the soil background value, which can be related to the long-term discharge of heavy metal wastewater from industrial enterprises around the sampling sites [9].

\subsection{Release experiments}

\subsubsection{Effect of different flow velocity}

The effect of flow velocity to heavy metal release from sediments was carried out through 30 days continuous experiments. The flow velocity was changed in the range from 0.6 to $1.2 \mathrm{~m} / \mathrm{s}$ while maintaining $\mathrm{pH}$ value at $7.7 \pm 0.2$ and the temperature at $25 \pm 1^{\circ} \mathrm{C}$ (in Fig. 2). In the inception phase, the contents of $\mathrm{Cu}, \mathrm{Zn}, \mathrm{Cd}$ and $\mathrm{Mn}$ in

Table 2. The concentrations of several heavy metal in the sediments of the Xiangjiang River.

\begin{tabular}{|c|c|c|c|c|c|c|c|c|c|}
\hline \multirow{2}{*}{ Sampling points } & \multirow{2}{*}{$\mathrm{pH}$} & \multicolumn{9}{|c|}{ Concentrations of heavy metal $(\mathrm{mg} / \mathrm{kg})$} \\
\cline { 3 - 11 } & & $\mathrm{Cu}$ & $\mathrm{Pb}$ & $\mathrm{Zn}$ & $\mathrm{Cd}$ & $\mathrm{Cr}$ & $\mathrm{Mn}$ & $\mathrm{As}$ & $\mathrm{Hg}$ \\
\hline $\mathrm{A}$ & 7.4 & 41.2 & 60.7 & 246 & 5.88 & 87.2 & 1862 & 60.1 & 0.287 \\
\hline $\mathrm{B}$ & 7.8 & 75.1 & 99.2 & 570 & 9.97 & 106 & 1801 & 121 & 0.455 \\
\hline $\mathrm{C}$ & 7.9 & 63.3 & 96.7 & 588 & 11.7 & 83.4 & 1024 & 119 & 0.411 \\
\hline $\mathrm{D}$ & 8.1 & 75.9 & 113.0 & 755 & 15.4 & 122 & 1464 & 109 & 0.608 \\
\hline E & 7.4 & 57.3 & 93.9 & 427 & 9.56 & 104 & 1881 & 116 & 0.502 \\
\hline Average & 7.7 & 62.56 & 92.70 & 517.20 & 10.50 & 100.52 & 1606.40 & 105.02 & 0.45 \\
\hline Standard deviation & 0.3 & 12.8 & 17.3 & 170.9 & 3.1 & 13.9 & 328.1 & 22.8 & 0.1 \\
\hline Standard-Grade III & $>6.5$ & $\leq 400$ & $\leq 500$ & $\leq 500$ & $\leq 1.0$ & $\leq 400$ & 583 & $\leq 40$ & $\leq 1.5$ \\
\hline
\end{tabular}

overlying water were $10.0 \mu \mathrm{g} / \mathrm{L}, 0 \mu \mathrm{g} / \mathrm{L}, 30.0 \mu \mathrm{g} / \mathrm{L}$ and $150.5 \mu \mathrm{g} / \mathrm{L}$, respectively. With the increase of flow velocity, the concentrations of $\mathrm{Cu}, \mathrm{Zn}, \mathrm{Cd}$ and $\mathrm{Mn}$ in overlying water increased regularly. When the flow velocity was $0.6 \mathrm{~m} / \mathrm{s}$, the released concentrations of $\mathrm{Cu}$, $\mathrm{Zn}, \mathrm{Cd}$ and $\mathrm{Mn}$ in overlying water were $14.8 \mu \mathrm{g} / \mathrm{L}, 33.0$ $\mu \mathrm{g} / \mathrm{L}, 0.4 \mu \mathrm{g} / \mathrm{L}$ and $323.5 \mu \mathrm{g} / \mathrm{L}$, respectively. Since the concentration of $\mathrm{Mn}$ in the sediments remains at a high level, the released amount of Mn was the highest value among these four heavy metals. When the flow velocity increased to $1.2 \mathrm{~m} / \mathrm{s}$, the release concentrations of $\mathrm{Cu}, \mathrm{Zn}$, $\mathrm{Cd}$ and $\mathrm{Mn}$ increased to $22.6 \mu \mathrm{g} / \mathrm{L}, 51.0 \mu \mathrm{g} / \mathrm{L}, 0.7 \mu \mathrm{g} / \mathrm{L}$ and $456.0 \mu \mathrm{g} / \mathrm{L}$, respectively. These results showed that the released concentration of heavy metals in the sediments increased as water flow velocity increased. The main reasons were as follows: (1) With the increase of water flow rate, the turbulence intensity of water increased, which make the diffusion reactions of heavy metals become faster between the sediments and overlying water, thus the exchange rate of heavy metals to pore-water was enhanced correspondingly [10], and increased the released amount of heavy metals. (2) The thickness of unconsolidated layers in the sediments were increased when the water flow velocity increased, which made the exchange velocity of interstitial water and overlying water more frequent, causing the increase of the dissolved oxygen in overlying water, thereby indirectly promoted the release amount of heavy metals from the sediments.
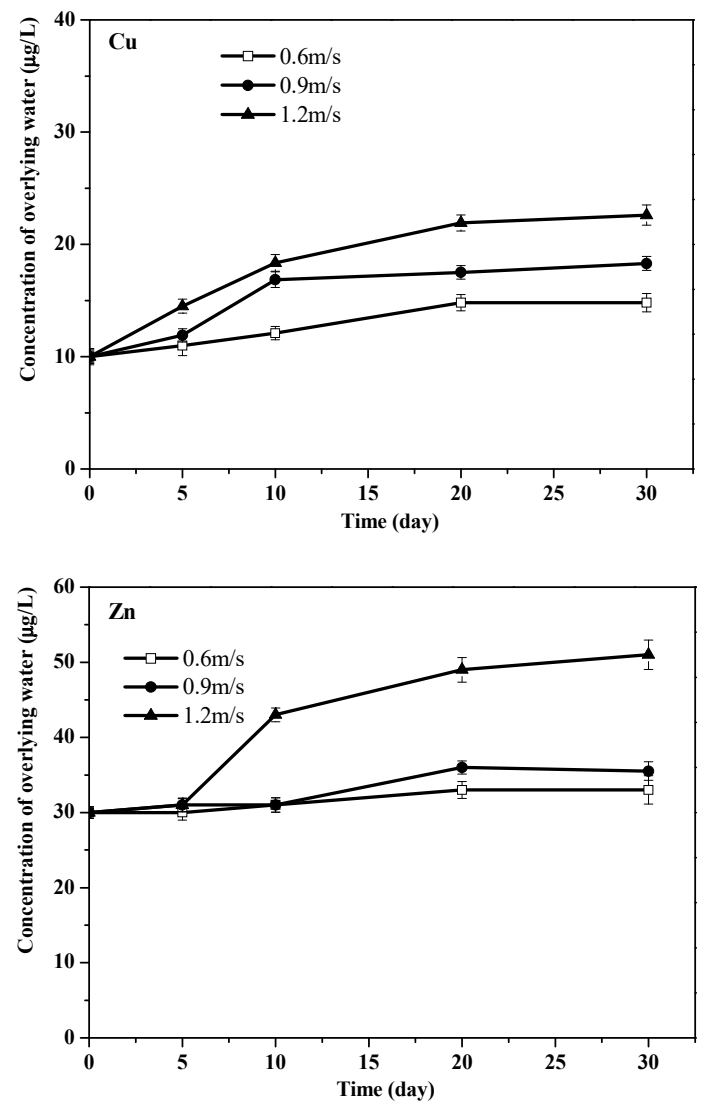

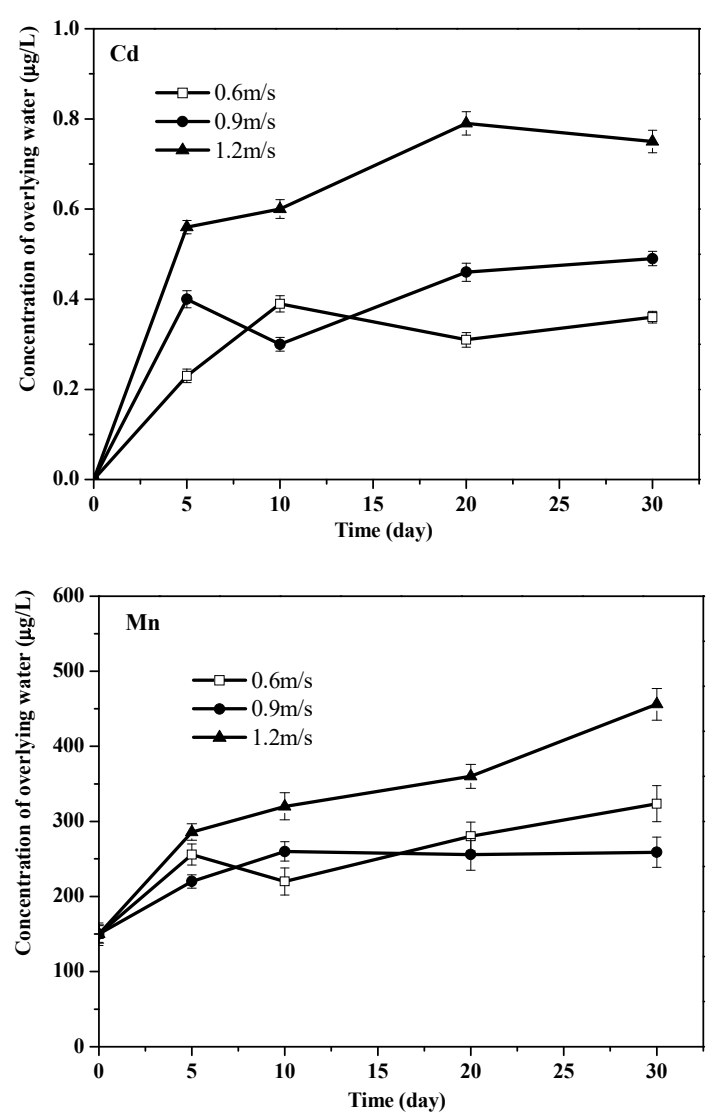

Fig. 2. The effect of flow velocity on the release of heavy metals from the sediments.

\subsubsection{Effect of different $\mathrm{pH}$ values}

The $\mathrm{pH}$ values of overlying water could affect the chemical forms of heavy metal thereby affect release of heavy metal from the sediments. When the $\mathrm{pH}$ value of overlying water increased from 6.0 to 9.0 (in Fig. 3), the release amount of $\mathrm{Cu}$ decreased from $1.15 \mu \mathrm{g} /(\mathrm{g} \cdot \mathrm{d})$ ) to $0.12 \mu \mathrm{g} /(\mathrm{g} \cdot \mathrm{d})$, and the release amounts of $\mathrm{Zn}$ and $\mathrm{Cd}$ decreased from $1.21 \mu \mathrm{g} /(\mathrm{g} \cdot \mathrm{d})$ to $0.12 \mu \mathrm{g} /(\mathrm{g} \cdot \mathrm{d})$ and from $0.618 \mu \mathrm{g} /(\mathrm{g} \cdot \mathrm{d}) \mathrm{dec}$ eased to $0.014 \mu \mathrm{g} /(\mathrm{g} \cdot \mathrm{d})$, respectively. The release amounts of $\mathrm{Cu}, \mathrm{Zn}$ and $\mathrm{Cd}$ were reduced nearly 8.58, 9.1 and 43.1 times, respectively. Meanwhile, the release amount of $\mathrm{Mn}$ also decreased from 7.50 $\mu \mathrm{g} /(\mathrm{g} \cdot \mathrm{d})$ to $2.61 \mu \mathrm{g} /(\mathrm{g} \cdot \mathrm{d})$. These results showed that the lower $\mathrm{pH}$ value of overlying water, the larger amount of heavy metals released from the sediments. When $\mathrm{pH}$ value decreased to 6.0 , the concentration of hydrogen ions in the overlying water were increased, which not only promoted the dissolution of the exchangeable and the carbonate-bound state of heavy metals, but also occupied the adsorptive sites of the sediments, thereby increasing the release amount of heavy metals indirectly [11]. The release amounts of four heavy metals were too small and the largest release amount of Mn was only 7.50 $\mu \mathrm{g} /(\mathrm{g} \cdot \mathrm{d})$, suggesting that the release of heavy metals from the sediments into the water environment is a slow and long-term process.

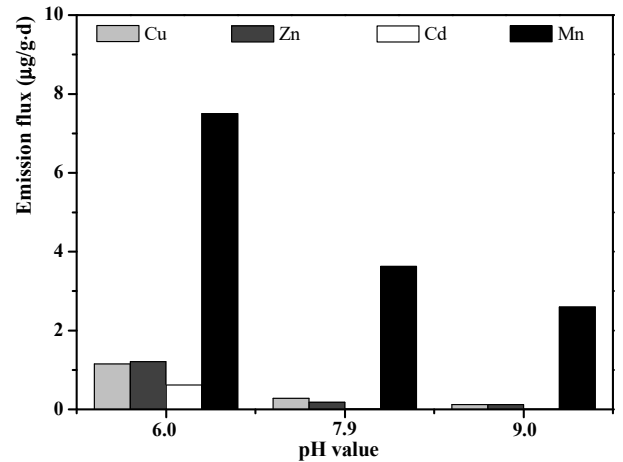

Fig. 3. The effect of $\mathrm{pH}$ value on the release of heavy metals from the sediments.

\section{Conclusions}

This study investigated the concentrations and the release amounts of heavy metals in the sediments of the Xiangjiang River. The $\mathrm{Cd}$ content of the sediments ranged from $5.88-15.40 \mathrm{mg} / \mathrm{kg}$ and the As content was $60.1-121.0 \mathrm{mg} / \mathrm{kg}$. Both $\mathrm{Cd}$ and As contents in the five sampling sites were significantly higher than the Grade III of the CEQSS. The release experiments showed that the increasing flow velocity and decreasing $\mathrm{pH}$ value of overlying water could promote the release of heavy metals from the sediments. The results also indicated that the release of heavy metals from the sediments into the overlying water is a slow and long-term process, since the largest release amount of $\mathrm{Mn}$ from the sediments was only $7.50 \mu \mathrm{g} /(\mathrm{g} \cdot \mathrm{d})$.

\section{Acknowledgment}

This work was supported by projects of the National Natural Science Foundation of China (NSFC) (Nos. 51709104), the National Water Pollution Control and Management Technology Major Projects (Nos. 2009ZX07212-001-07), the Natural Science Foundation of Hunan Province (Nos. 2017JJ3148) and the Key Research and Development Program in Hunan Province (Nos.2017SK2381).

\section{References}

1. M. Jiang, G.M. Zeng, C. Zhang, X.Y. Ma, M. Chen, J.C. Zhang, L.H. Lu, Q. Yu, L.P. Hu, L.F. Liu. Plos One, 8, 8 (2013)

2. C.N. Han, Y.W. Qin, B.H. Zheng, Y.Q. Ma, L. Zhang, W. Cao. Environ. Earth Sci., 72 (2014)

3. T. Zoumis, A. Schmidt, L. Grigorova. Sci. Total Environ., 266, 3 (2001)

4. L. Wang, Z.H. Guo, X.Y. Xiao, T.B. Chen, X.Y. Liao, J. Song, B. Wu. J. Geogr. Sci., 18, 3 (2008)

5. L.Y. Chai, H. Li, Z.H. Yang, X.B. Min, Q. Liao, Y. Liu, S.H. Men, Y.N. Yan, J.X. Xu. Environ. Sci. Pollut. R., 24, 1 (2017)

6. J. Qi, H. Zhang, X. Li, J. Lu, G. Zhang. Environ. Monit. Assess, 188 (2016) 
7. Y. Zhu. Academic dissertation, Hunan Normal University, 2013

8. Environmental Monitoring of China. China Environmental Science Press, 1990

9. Y.Z. Xu, J.J. Liu, Y.X. Cheng, Y.Z. Dai, G.Y. Fu. Environ. Chem., 35, 1 (2016)

10. Z.G. Li. Academic dissertation, China University of Mining and Technology, 2009

11. Y.Z. Gao, H.J. Zheng, W.T. Ling, H.Q. Hu, F. Liu. China Environ. Sci., 22, 3 (2002) 